\title{
OTIMIZAÇÃO DO PROCESSO DE EXTRAÇÃO DE ÓLEO DE LICURI
}

\author{
Tamila Ferreira Pereira ${ }^{1}$ e Andrea Limoeiro Carvalho ${ }^{2}$ \\ 1. Bolsista PROBIC, Graduanda em Engenharia de Alimentos, Universidade Estadual de Feira de Santana, e-mail: \\ tamilaferreira1@gmail.com \\ 2. Orientador, Departamento de Tecnologia, Universidade Estadual de Feira de Santana, e-mail: \\ limoeiro@uefs.br
}

PALAVRAS-CHAVE: Extração, Prensagem, Óleo de licuri.

\section{INTRODUÇÃO}

O Licuri é uma palmeira nativa do território brasileiro, sendo seu nome científico Syagrus coronata. A mesma é natural do sul de Pernambuco, Alagoas e Sergipe, abrangendo toda a região norte de Minas Gerais e toda a região central, oriental e sul da Bahia, onde é mais comumente encontrada, portanto observa-se que é uma planta típica do semiárido nordestino, já que uma das suas principais características é a preferência por regiões secas e áridas da Caatinga (NOBLICK, 1986).

É uma palmeira que produz grandes quantidade de frutos anualmente, uma vez que floresce e frutifica durante todo o ano, mas apresenta maior frutificação entre maio e agosto, e o amadurecendo ocorre no período de outubro a dezembro (LORENZI, 1992). Embrapa (2007), afirma que os frutos são constituídos de polpa e amêndoas, que quando secos, possuem casca dura e coloração escura, revestindo uma amêndoa rica em óleo. Conforme Bondar (1938), as amêndoas possuem alto teor de lipídios e quando secas possibilita a extração de $38 \%$ (do total) de um óleo incolor, transparente e de densidade de $0,921 \mathrm{~kg} / \mathrm{dm}^{3}$ a $15^{\circ} \mathrm{C}$. A análise da composição nutricional do fruto do licuri realizada por Crepaldi et al. (2001) demonstrou que as amêndoas possuem alto teor de lipídeos, em média 49,2\%, já a polpa, 4,5\% de lipídeos.

$\mathrm{O}$ rendimento da extração do óleo depende do método a ser utilizado, assim como de alguns parâmetros, tais como a pressão aplicada sobre a massa de grãos e o preparo prévio da matéria-prima a ser processada, como temperatura de prensagem, e teor de umidade das amostras que por sua vez é o fator que mais influencia na quantidade de óleo residual na torta (SINGH et al., 2002, apud PIGHINELLI et al. 2009). Para maior contribuição no uso total da planta, o resíduo da prensagem, além de ser designada a ração animal pode ser utilizado para a obtenção de princípios bioativos, como por exemplo enzimas, uma vez que possui uma constituição nutricional favorável ao crescimento microbiano. No entanto, para a torta ser utilizada como meio fermentativo, esta deve apresentar baixo teor de óleo resultante após a extração por prensagem, possibilitando a absorção da quantidade de água necessária para se obter uma umidade que favoreça este crescimento microbiano em uma fermentação semissólida.

Para aperfeicoar a eficiência da extração, visando atender as comunidades produtoras de licuri o presente trabalho propõe otimizar o processo de extração de óleo de licuri por prensagem visando a identificação das principais variáveis envolvidas no processo e a implementação dessa nova tecnologia para o desenvolvimento de produtos de elevado valor agregado. 


\section{METODOLOGIA}

Para a realização do presente trabalho foram tomadas amostras de sementes de licuri (Syagrus coronata) úmidas (sem sofrer processo de torrefação) e torradas, provenientes da Cooperativa de Produção da Região do Piemonte da Diamantina (COOPES), localizada na microrregião de Piemonte da Diamantina. As matérias-primas recebidas passaram por um pré-tratamento, na qual foi realizada a fragmentação das amêndoas com a utilização de um liquidificador industrial (Skymsen, LB-25).

Posteriormente efetuou-se a realização das análises físico-químicos do licuri recebido da cooperativa, tais como a análise do teor de umidade inicial, por métodos gravimétricos, utilizando a metodologia do Instituto Adolfo Lutz (1985), o de teor de lipídeos pelo método de Blight e Dyer (1959), e por fim o teste de saturação, determinado pelo procedimento descrito por Sosulski (1962) citado por Wang et al. (2006), com o objetivo de caracterizar a matéria-prima.

Após o procedimento de caracterização das amostras, identificou-se os limites dos parâmetros de estudo, umidade e temperatura, através da revisão bibliográfica do tema em materiais diversos, que serviram de subsídio e permitiram selecionar as variáveis a serem avaliadas no planejamento experimental DCCR (Delineamento Cenrtal Composto Rotacional) para as diferentes amostras de licuir, variando entre $25^{\circ} \mathrm{C}$ e $60^{\circ} \mathrm{C}$ de temperatura, e com umidades variando entre $4,8 \%$ e $12 \%$ para a amêndoa úmida e $0,3 \%$ e $3,9 \%$ para a amêndoa torrada.

Depois destes processos, deu-se início a execução das extrações que foram antecedidas pelo pré-tratamento com acondicionamento da umidade das amêndoas por aspersão de água. Para cada ensaio de prensagem foram utilizados $150 \mathrm{~g}$ de amêndoas em conjunto com a massa de água necessária para a adequação dos níveis de umidade contidos no planejamento experimental. Após a coleta dos dados obtidos com a execução deste planejamento sucedeu-se a avaliação estatística destes, através do software Statistica7.0.

\section{RESULTADOS}

Neste trabalho adotou-se dois planejamentos experimentais, que diferiram entre si somente na faixa de teor de umidade estudada e no tipo de amêndoas (úmidas e torradas) analisadas. O primeiro, utilizou um DCCR para a amostra úmida, o que permitiu avaliar os efeitos da temperatura de extração e umidade da amêndoa, ao nível de $0,1 \%$ de significância, sobre o rendimento da extração do óleo da amostra úmida. A resposta foi expressa por um modelo matemático (Equação 1), que contém apenas os efeitos que influenciaram significativamente o processo. Pode-se observar na Equação 1 , cujo coeficiente de determinação $\left(\mathrm{R}^{2}\right)$ foi de $84,99 \%$, que ambas as variáveis afetaram o processo, sendo que a variável com maior efeito foi o termo linear da umidade, que atua de forma negativa, indicando que quanto menor a umidade da amêndoa maior será o rendimento em óleo bruto.

$$
\text { Rend. }(\%)=10,998+2,736 * T\left({ }^{\circ} \mathrm{C}\right)-4,858 * U(\%)
$$

A partir dos resultados obtidos com a amêndoa úmida foram definidos os limites de umidade a serem estudados para a amostra torrada, que também foi submetida ao mesmo tipo de estudo. Através da análise de regressão múltipla dos dados experimentais, obteve-se o modelo estatístico (Equação 2), com coeficiente de determinação $\left(\mathrm{R}^{2}\right)$ de $81,89 \%$, composto apenas pelos parâmetros que influenciaram significativamente na resposta $(\mathrm{p}<0,1)$, no qual se verifica que os termos lineares e 
quadráticos do teor de umidade influenciaram no rendimento da extração, sendo este mais sensível à variação do termo quadrático da umidade, quando a umidade é superior a $1 \%$, e atua de forma negativa, mas se a umidade for menor ou igual a $1 \%$, o termo linear da umidade passar a ter maior influência, e atua de forma positiva, denotando que quanto maior for a umidade da amêndoa maior será o rendimento em óleo. Para a faixa de umidade estudada, a temperatura não influenciou significativamente no processo.

$$
\text { Rend. }(\%)=37,215+3,020 * U(\%)-2,201 * U^{2}(\%)
$$

Através da análise da superfície de resposta e curva de contorno geradas para as amostras de licuri úmido e torrado, Figuras 1 e 2, pode-se visualizar, dentro dos intervalos avaliados, as condições de temperatura e umidade em que há uma maior extração de óleo, que, para o licuri úmido (Figura 1), são as de maior temperatura das amêndoas e menor teor de umidade. Em condições de temperaturas e umidade de aproximadamente $60^{\circ} \mathrm{C}$ e $5,8 \%$, respectivamente, obteve-se um rendimento mais elevado, em torno de $18 \%$. Na Figura 2 é possível observar o efeito das variáveis estudadas sobre o rendimento da extração de óleo de licuri da amostra torrada, onde se observa que o maior rendimento em óleo, acima de 38\%, ocorre entre 2,1 a 3,4\% de umidade e independem da temperatura, como já foi demostrado pela Equação 2. Na Figura 2a é possível ainda verificar a existência de uma relação quadrática da umidade e uma linear da temperatura, praticamente constante, com o rendimento.
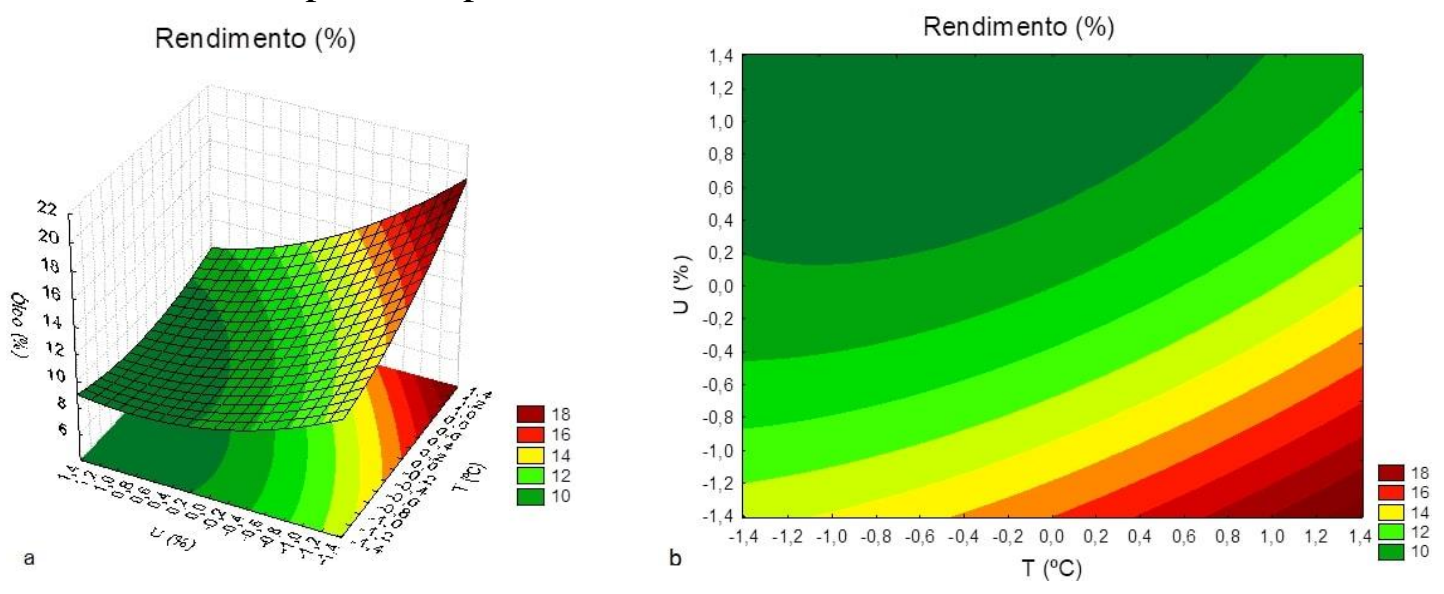

Figura 1 - Superfície de resposta (a) e curva de contorno (b) para o rendimento de óleo bruto em função do teor de umidade e temperatura das amêndoas de licuri úmido.
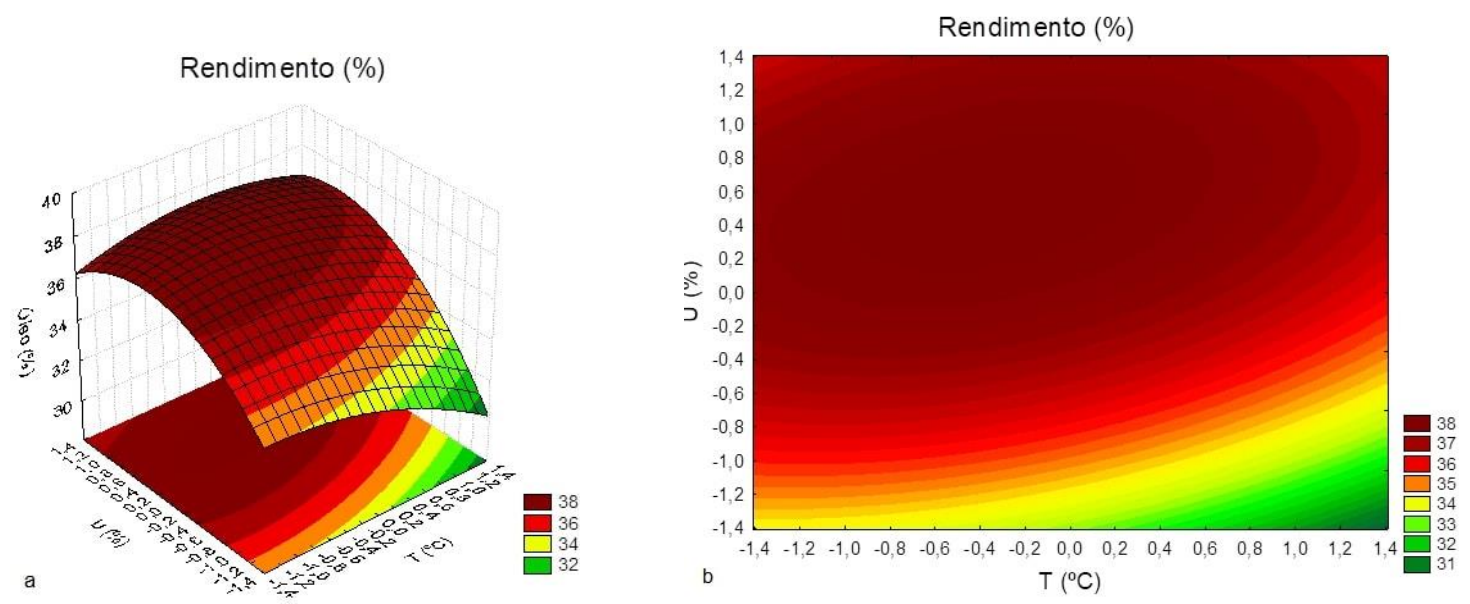

Figura 2 - Superfície de resposta (a) e curva de contorno (b) para o rendimento de óleo bruto em função do teor de umidade e temperatura das amêndoas de licuri torrado. 


\section{Conclusão}

Os resultados apresentados no presente trabalho para as duas amostras permitiram identificar que a umidade é o parâmetro que mais afeta no rendimento, assim como a existência de uma faixa ótima de teor de umidade, que podem ser obtidos com o tratamento prévio da matéria-prima. O teor de umidade entre 2,1 a 3,4\%, correspondendo ao máximo rendimento em óleo, acima de $38 \%$.

O estudo realizado apontou que a temperatura não influencia no rendimento quando a umidade do grão é muito baixa, no entanto, quando há uma alta umidade, a temperatura influencia significativamente e de forma positiva, sendo assim, em condições de elevada umidade, quanto maior a temperatura maior é o rendimento.

\section{REFERÊNCIAS}

BLIGH, E. G.; DYER, W. J. A rapid method of total lipid extraction and purification. Canadá: Canadian journal of biochemistry and physiology, v. 37, n. 8, p. 911-917, 1959.

BONDAR, G. O licurizeiro (cocus coronata Mart.) e suas potencialidades na economia brasileira. Salvador: Instituto Central de Fomento Econômico da Bahia, 1938. 18 p.

CREPALDI, I. C.; ALMEIDA-MURADIAN, L. B. de.; RIOS, M. D. G.; PENTEADO, M. de V. C.; SALATINO, A. Composição nutricional do fruto de licuri (Syagrus coronata (Martius) Beccari). São Paulo: Revista Brasileira Botânica, v. 24, n. 2, 2001.

EMBRAPA SEMIÁRIDO. DOCUMENTOS, 199. Licuri Syagrus coronata (Mart.) Becc/Marcos Antônio Drumond. Petrolina: Embrapa Semiárido, 2007.

INSTITUTO ADOLFO LUTZ. Normas analíticas do Instituto Adolfo Lutz: métodos químicos e físicos para análise de alimentos. 3.ed. São Paulo: Instituto Adolfo Lutz, p. 98, 1985.

LORENZI, H. Árvores brasileiras: manual de identificação e cultivo de plantas arbóreas nativas do Brasil. Nova Odessa: Ed. Platarum, p. 287, 1992.

NOBLICK, L. R.; Palmeiras das caatingas da Bahia e as potencialidades econômicas. Simpósio sobre a Caatinga e sua Exploração Racional. Brasília: EMBRAPA, 1986.

PIGHINELLI. et al. Otimização da prensagem de grãos de girassol e sua caracterização. Campina Grande: Bras. Eng. Agríc. Ambiental, v.13, n.1, p. 63-67, 2009.

SINGH et al. Influence of Moisture Content and Cooking on Screw Pressing of Crambe Seed. JAOCS, v. 79, n. 2, 2002.

WANG, S. H.; ROCHA, G. O.; NASCIMENTO, T.; ASCHERI, J. L. R. Absorção de água e propriedades espumantes de farinhas extrusadas de trigo e soja. Campinas: Ciência e Tecnologia de Alimentos, v. 26, n. 2, 2006. 